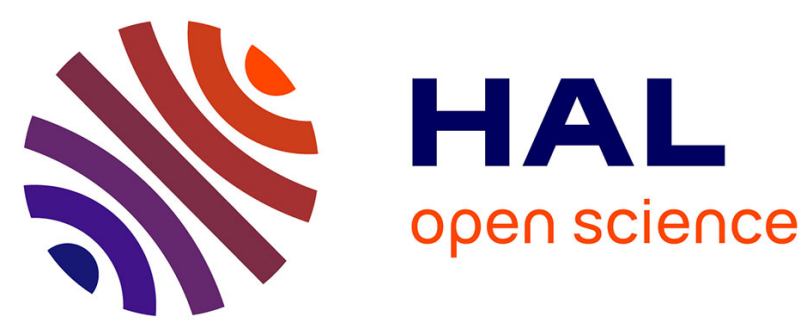

\title{
Lithium Ferrite Nanocrystals Embedded in a non-Magnetic Glass Matrix
}

\author{
E. Rezlescu, N. Rezlescu, M. Craus
}

\section{To cite this version:}

E. Rezlescu, N. Rezlescu, M. Craus. Lithium Ferrite Nanocrystals Embedded in a nonMagnetic Glass Matrix. Journal de Physique IV Proceedings, 1997, 07 (C1), pp.C1-553-C1-554. 10.1051/jp4:19971228 . jpa-00254901

\section{HAL Id: jpa-00254901 https://hal.science/jpa-00254901}

Submitted on 1 Jan 1997

HAL is a multi-disciplinary open access archive for the deposit and dissemination of scientific research documents, whether they are published or not. The documents may come from teaching and research institutions in France or abroad, or from public or private research centers.
L'archive ouverte pluridisciplinaire HAL, est destinée au dépôt et à la diffusion de documents scientifiques de niveau recherche, publiés ou non, émanant des établissements d'enseignement et de recherche français ou étrangers, des laboratoires publics ou privés. 


\title{
Lithium Ferrite Nanocrystals Embedded in a non-Magnetic Glass Matrix
}

\author{
E. Rezlescu, N. Rezlescu and M.L. Craus \\ Institute of Technical Physics, Bd. Mangeron 47, 6600 Iasi, Romania
}

\begin{abstract}
Nanocrystalline $\mathrm{LiFe}_{5} \mathrm{O}_{8}$ particles embedded in an amorphous matrix were obtained by heat treatments of the nonmagnetic oxide glass $32 \mathrm{Li}_{2} \mathrm{O}-8 \mathrm{FeO} \mathrm{O}_{3}-60 \mathrm{~B}_{2} \mathrm{O}_{3}$, between 200 and $770^{\circ} \mathrm{C}$. The X-ray spectra reveal the formation of the spinel phase of Li-ferrite in the initially amorphous materials only for annealing temperatures higher than $440^{\circ} \mathrm{C}$ and the hybrid structure becomes more evident with the increase of temperature. The occurrence of the magnetic spinel phase $\left(\mathrm{LiFe}_{5} \mathrm{O}_{8}\right)$ was proved by magnetization and Curie temperature measurements too. The evolution of the magnetic properties of these glass-ceramic compounds in terms of annealing temperature was investigated. The magnetic properties $\left(\sigma_{s}, H_{c}\right)$ are correlated with the average size of the $\mathrm{LiFe}_{5} \mathrm{O}_{8}$ nanoparticles dispersed in the glass matrix. The X-ray diffraction data indicated an evident increase in the average crystal block size from 3.5 to $50 \mathrm{~nm}$ with the increase of annealing temperature from $440^{\circ}$ to $770^{\circ} \mathrm{C}$.
\end{abstract}

In an earlier paper [1] we shown that by thermal annealing of the metastable oxide glasses $32 \mathrm{Li}_{2} \mathrm{O}-8 \mathrm{Fe}_{2} \mathrm{O}_{3}-60 \mathrm{~B}_{2} \mathrm{O}_{3}$ occurs the crystallization of $\mathrm{Li}$-ferrite $\left(\mathrm{LiFe}_{5} \mathrm{O}_{8}\right)$ and the resulting material is a glass-ceramic named ferriglass. Crystals of ferrite, randomly dispersed in the amorphous matrix, of nanometer sizes $(3.5 \mathrm{~nm}$ to $50 \mathrm{~nm}$ ) depending on the annealing temperature, were obtained. The irreversible changes in the structure of the amorphous matrix was investigated by $\mathrm{X}$-ray analysis and magnetic measurements. In this work we extend previous report dealing with the relationship among thermal annealings, crystal size and magnetic properties of the glass-ceramic containing lithium ferrite nanoparticles.

The amorphous ribbons were fabricated by rapid quenching of the liquid state between two cooper rollers. The resulting ribbons were $3-5 \mathrm{~mm}$ wide and 10-20 $\mu \mathrm{m}$ thick. The details of the sample procedure are described in [1]. The amorphous structure of the ribbons was confirmed by X-ray diffraction. The specimens were successively annealed at various temperatures between $200-770^{\circ} \mathrm{C}$. The mean grain size of the Li-ferrite crystallites was determined using Scherrer's formula. The magnetic measurements were carried out with a vibrating sample magnetometer

The occurrence of $\mathrm{LiFe}_{5} \mathrm{O}_{8}$ magnetic phase in the amorphous nonmagnetic compound $\mathrm{Li}_{2} \mathrm{O}-\mathrm{Fe}_{2} \mathrm{O}_{3}-\mathrm{B}_{2} \mathrm{O}_{3}$ was revealed by magnetization measurement during the rapid heating of the amorphous ribbons between $20-700^{\circ} \mathrm{C}$. Fig 1 displays the variation of the specific magnetization $\sigma_{\mathrm{s}}$ measured at $8.8 \mathrm{kOe}$ versus temperature and shows several interesting facts: i)up to about $500^{\circ} \mathrm{C}$ there is no appreciable magnetization; ii)the descendent curve between $500-600^{\circ} \mathrm{C}$ shows the same shape with a weak ferrimagnetic material; iii)the Curie point $\left(660 \pm 10^{\circ} \mathrm{C}\right)$ is very close to that measured on the $\mathrm{LiFe}_{5} \mathrm{O}_{8}$ single crystals grown in our laboratory by the flux method [2]. This later concordance attests the crystallization of the Li ferrite.

To investigate the thermal behaviour of the amorphous compound $\mathrm{Li}_{2} \mathrm{O}-\mathrm{Fe}_{2} \mathrm{O}_{3}-\mathrm{B}_{2} \mathrm{O}_{3}$, the same specimen was subjected to successive thermal annealings, between 200 and $770^{\circ} \mathrm{C}$ for a long time ( $2 \mathrm{~h}$ for each annealing). The $\mathrm{X}$-ray analysis revealed the start of the spinel phase nanocrystallization after annealing at about $440^{\circ} \mathrm{C}$. The occurrence of the magnetic phase was proved by magnetization and Curie temperature measurements. No evidence of magnetic ordering has been detected up to $440^{\circ} \mathrm{C}$. The obtained results for annealed samples are compiled in Table 1. With increasing $T_{a}, \sigma_{s}$ increases up to a value of $\sim 12 \mathrm{emu} \mathrm{g}^{-1}$. An abruptly increase in $\sigma_{\mathrm{s}}$ can be noticed for samples annealed in the temperature range $440-530^{\circ} \mathrm{C}$, due to the Liferrite crystallization. The saturation like behaviour of $\sigma_{\mathrm{s}}$ for high temperatures is the result of the crystallization of the whole amount of $\mathrm{Li}$ ferrite within the glass host. Of course, due to the dispersion of the ferrite particles in a non-magnetic residual phase, $\sigma_{s}$ value of this ferriglass material is much lower than that reported for bulk lithium ferrite $\left(62.5 \mathrm{emug}^{-1}\right)$. Thus the $\sigma_{s}$ values may give information on the percentage of $\mathrm{LiFe}_{5} \mathrm{O}_{8}$ crystallized in the amorphous network. We estimated it after each thermal annealing.(Table 1). One can observe an increase of the percentage from 1 to $19 \%$ when $T_{a}$ increases from 440 to $770^{\circ} \mathrm{C}$. At high temperatures a slow increase of this percentage was evaluated, that can be explained by finishing of the crystallization process of the Li ferrite. From Table 1 one remarks an increase of the mean grain size $\bar{D}$ from $3.5 \mathrm{~nm}$ to $50 \mathrm{~nm}$ with increasing of $T_{a}$. A pronounced increase of the crystallites was noticed for annealing above $580^{\circ} \mathrm{C}$. Two simultaneous process seem to take place at higher temperatures: a normal grain increase due to the progressive crystallization and, on the other hand, a formation of agglomerated clusters, in which the larger grains grow at the expense of the smaller by a "penetrating" process. A special attention is given to the relationship between the grain size of $\mathrm{LiFe}_{5} \mathrm{O}_{8}$ nanoparticles and the 
magnetic properties $\left(\sigma_{s}, H_{c}\right)$ of the vitroceramic material. Fig 2 reveals $\sigma_{s}$ and $H_{\mathrm{c}}$ as a function of mean grain size $\bar{D}$. The sharp increase of $\sigma_{s}$ for small grain sizes (at low annealing temperatures) may

\begin{tabular}{|l|c|l|c|l|}
\hline $\begin{array}{l}\mathrm{T}_{\mathrm{a}} \\
\left({ }^{0} \mathrm{C}\right)\end{array}$ & $\begin{array}{c}\sigma_{\mathrm{s}} \\
\left(\mathrm{emu.g}^{-1}\right)\end{array}$ & $\begin{array}{l}\mathrm{H}_{\mathrm{c}} \\
(\mathrm{Oe})\end{array}$ & $\begin{array}{l}\mathrm{D} \\
(\mathrm{nm})\end{array}$ & $\begin{array}{l}\mathrm{LiFe}_{5} \mathrm{O}_{8} \\
(\%)\end{array}$ \\
\hline 200 & - & - & - & \\
\hline 440 & 0.60 & - & 3.5 & 1.05 \\
\hline 480 & 5.90 & - & 5.0 & 9.44 \\
\hline 530 & 10.12 & - & 6.0 & 16.19 \\
\hline 580 & 10.60 & 26.5 & 13.3 & 16.70 \\
\hline 630 & 11.06 & 40.2 & 20.0 & 17.70 \\
\hline 680 & 11.57 & 58.4 & 28.0 & 18.51 \\
\hline 720 & 11.73 & 29.1 & 37.0 & 18.77 \\
\hline 770 & 11.88 & 40.0 & 49.5 & 19.07 \\
\hline
\end{tabular}

Table 1: Material parameters vs. annealing temperature be explained by the multiplication of the nucleation centres that leads to a rapid increase of the crystallization percentage of the Li ferrite.. At higher temperatures (above $580^{\circ} \mathrm{C}$ ) the increase of the grains by penetrating process dominates and determines a slight increase of the magnetization. The relationship between $\sigma_{\mathrm{s}}$ and $\bar{D}$ is found to be: $\sigma_{s} \sim \bar{D}^{3}$, for $\bar{D}<\bar{D}$, and $\sigma_{s} \sim \bar{D}^{0,08}$ for $\bar{D}>\bar{D}_{i}$. From the fig 2 one observes that $\mathrm{H}_{\mathrm{c}}$ increases with the increasing grains, and then, for a further increase of the grains, it decreases. This decrease is attributed to the transition from single to multidomain magnetization mechanism (it is easier to displace a domain wall than to rotate the individual atomic spins). In this connection we estimate the critical size for a single domain particle with formula[3]: $\bar{D}_{c r i}=\left(9 \sigma_{w} / 2 \pi M_{s}^{2}\right)$, where $\sigma_{w}=\left(2 k_{b} T_{c} / K_{i} / / a\right)^{1 / 2}$ is the wall density energy, $/ K_{I} /$ is the anisotropy constant, $T_{c}$ the Curie point, $M_{s}$ the saturation magnetization and a the lattice constant. Using $/ K_{1} /=8 \cdot 10^{4}$ $\mathrm{erg} / \mathrm{cm}^{3}[4], M_{s}=310 \mathrm{G}, a=8.37 \cdot 10^{-8} \mathrm{~cm}, T_{c}=933 \mathrm{~K}$, it was obtained $\bar{D}$ ${ }_{c r i}=75 \mathrm{~nm}$. For the mean sizes $\bar{D}>75 \mathrm{~nm}$, the particle is already multidomain. Below this size, the particle is a uniformly magnetized single-domain. However, there is a lower limit, $\bar{D}_{i}$, i.e. a particle size below which a super-paramagnetic state appears, estimated as $\bar{D}_{i}=6 \mathrm{~nm}$ according to [5] (fig. 2). For $\bar{D}<\bar{D}_{i}$ no measurable coercivity is found. Therefore, the main size of the single domain crystallites should be in the range of $30-40 \mathrm{~nm}$, in good agreement with our results.

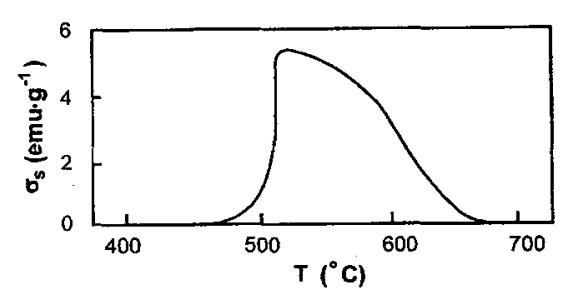

Figure 1: $\sigma_{s}$ versus temperature for an amorphous sample

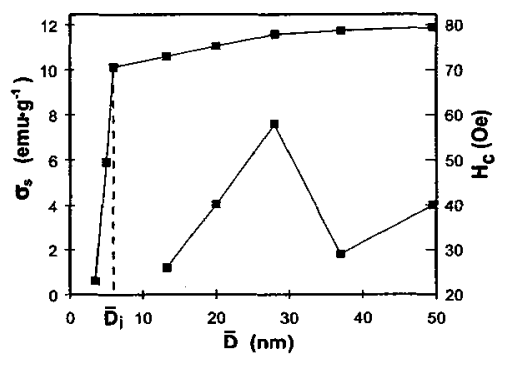

Figure 2: $\sigma_{\mathrm{s}}$ and $H_{c}$ versus mean grain size $\bar{D}$

To give an interpretation of the $\bar{D}_{\text {crit }}$ we used the exchange length expressed by $l_{e x}=\left[A / 4 \pi M_{s}^{2}\right]^{l i 2}$. This parameter represents the appropriate length scale for homogeneous magnetization in a soft magnetic material. The exchange constant $A=\left(2 . \mathrm{S}^{2} / a\right)$ [5] was evaluated as $6,75 \mathrm{erg} / \mathrm{cm}$. Thus: $\bar{D}_{c r i t}=10 l_{e x}$. This relation is in good agreement with Kneller's critical diameter for single domain behaviour of a spherical particle[6]. Therefore the stability of the homogeneous magnetized states sensitively depends on the ratio of particle size to exchange length. For larger ratio, i.e. $\bar{D} / l_{c x}>10$, an inhomogeneous magnetization occurs caused by multidomain configuration.

In conclusion, the magnetic properties of the glass ceramic containing $\mathrm{Li}$ ferrite are closely related to the crystal sizes of the $\mathrm{LiFe}_{5} \mathrm{O}_{8}$ developed in $\mathrm{Li}_{2} \mathrm{O}-\mathrm{Fe}_{2} \mathrm{O}_{3}-\mathrm{B}_{2} \mathrm{O}_{3}$ glass by thermal annealings. Thus, the fine control of the crystal growth by the manipulation of the annealing temperature can be exploited for the production of glass-ceramics with predetermined properties. Also glass crystallization by heat treatments offers a facile possibility to obtain powders of nanometer size magnetic particles for many practical applications.

\section{References}

[1] Rezlescu N., Rezlescu E., Pasnicu C., Craus M.L., J.M.M.M. 131 (1994) 273-277.

[2] Rezlescu E., Rezlescu N., Craus M. L., Pasnicu C,, Rezlescu L., Cryst. Res. Technol. (1996) in press.

[3] Kittel Ch, Galt J., Sol. State Phys. 3, N.Y. (1956) 437.

[4] Arai Ken Ichi and Tsuya Noburu, J. Phys. Soc. Jap. 33 (1972) 1581-1583.

[5] Vonsovski S.V., Magnetism (Bucharest, 1981) 1088-1090.

[6] Kneller E., Handbuch der Physik, vol. XVIII/2 (Springer, Berlin 1966). 